\title{
COMPARISON OF WASTE DUE TO IRRADIATED STEELS IN THE ESFR AND DEMO
}

\author{
Jack Reid ${ }^{1}$, Greg Bailey², Edmund Cracknell ${ }^{3}$, Mark Gilbert ${ }^{2}$, and Lee Packer ${ }^{2}$ \\ ${ }^{1}$ Nucleargraduates \\ ENERGUS, Blackwood Road, Lillyhall, CA14 4JW \\ ${ }^{2}$ Culham Centre for Fusion Energy \\ Culham Science Centre, Abingdon OX14 3EB \\ ${ }^{3}$ Magnox Ltd. \\ Oldbury Technical Centre, Oldbury BS35 1RQ
}

Jack.Reid@nucleargrads.com, Greg.Bailey@ukaea.uk, Edmund.Cracknell@magnoxsites.com,
Mark.Gilbert@ukaea.uk, Lee.Packer@ukaea.uk

\begin{abstract}
For either nuclear fusion or generation IV fission reactors to be viable as a commercial energy source the decommissioning and waste disposal solutions must be considered during the design. A multi-step simulation process combining Monte Carlo Neutron Transport simulations with inventory simulations have been performed to estimate the activation of steels in key reactor components of the European Sodium-cooled fast Reactor (ESFR). Waste classifications based on UK waste disposal regulations have been applied to the key components to estimate the expected masses of low level and intermediate level waste. The use of reduced activation steels, EUROFER and F82H, in reactor components external to the core results in a factor of 10 reduction in the percentage of waste classified as Intermediate Level Waste (ILW). Waste estimates are compared to existing waste estimates for the European Demonstration fusion reactor (DEMO). The ESFR has a lower percentage of ILW per total reactor mass due to irradiated steels compared to DEMO. However, there is no Higher Activity Waste (HAW) associated with DEMO, compared with arisings from the ESFR spent fission fuel.
\end{abstract}

KEYWORDS: Waste, Fission, Fusion, MCNP, FISPACT-II

\section{INTRODUCTION}

For all power generating nuclear reactors, fission or fusion, it is essential to consider decommissioning and radioactive waste management strategies during the design phase of the plant. The key factor in determining the economic and environmental impacts of disposing radioactive waste is its waste categorization. There are three main waste categories; Higher Activity Waste (HAW), Intermediate Level Waste (ILW), and Low-Level waste (LLW) [1]. The technical complexity and cost associated with the storage and disposal of waste drastically decreases as waste moves down through the waste categories towards LLW. 
Research has been carried out for the European Demonstration fusion reactor (DEMO) to estimate the expected waste arisings from irradiated structural components [2]. This research suggests that, while the DEMO reactor is not expected to produce any HAW, there are large volumes of long-lived ILW arising due to high energy, $14 \mathrm{MeV}$, neutrons generated in the Deuterium-Tritium (DT) plasma irradiating structural steels.

Fission reactor waste estimates traditionally focus on the HAW associated with the fuel cycle and minor actinides, as it poses a higher radiological risk than ILW associated with irradiated structural components. However, one of the key design goals for generation IV (Gen IV) fission reactors is that they will minimise and manage their nuclear waste and notably reduce the long-term stewardship burden [3]. To achieve this goal many Gen IV reactor designs are based on a closed fuel cycle in which plutonium generated in the fuel are burned in the reactor instead of being removed as waste, reducing the volume of HAW. The European Sodium-cooled Fast Reactor (ESFR) is an example of Gen IV fission reactor design incorporating a closed fuel cycle.

The Gen IV technology roadmap estimates that a Sodium-cooled Fast Reactor (SFR) demonstration reactor will be in operation by the 2030s [3]. Construction of the DEMO fusion reactor is expected to start in the late 2030s [4]. It is not unreasonable to assume that the DEMO fusion reactor and an ESFR style reactor would be decommissioned in the same time period. The material choices made in the design phase will have a direct effect on the waste implications of the reactor; reducing the proportion of ILW has a great benefit to the economic and environmental impact of decommissioning. This paper investigates the waste burden of potential steel alloys for key reactor components for the ESFR. The overall waste burden of the ESFR is compared to that of DEMO, as estimated in the work of Gilbert et al. [2].

\section{METHODOLOGY}

The activity of key steel reactor components in ESFR; fuel cladding, Intermediate Heat Exchangers (IHXs), sodium pumps and the reactor containment vessel were calculated using methodology similar to that developed in [1]. The Monte Carlo Neutral Particle Transport code (MCNP6.2) [5] was used to simulate the neutron flux within the key reactor components. Using the simulated neutron fluxes the inventory simulation code FISPACT-II [6] using the nuclear data library TENDL-2017 [7] calculated the activation of different steel alloys for the reactor components. The activities of the reactor components were compared to UK radioactive waste disposal limits to determine its severity as a function of time. Waste with a specific $\alpha$ activity $<4 \times 10^{6} \mathrm{~Bq} \mathrm{~kg}^{-1}$ and a combined total $\beta+\gamma$ activity $<1.2 \times 10^{7} \mathrm{~Bq} \mathrm{~kg}^{-1}$ is categorised as LLW [8] while arisings above these limits is classified as ILW. The total mass of LLW and ILW associated with the ESFR were calculated for decay times 1 and 1000 years after reactor shutdown.

\subsection{ESFR Reactor Specifications}

The dimensions of the reactor vessel, the pumps, and the IHXs were estimated using diagrams and concept models shown in [9] and [10]. Figure 1 shows the MCNP geometry of the ESFR reactor. The MCNP geometry of the reactor core is shown in more detail in Figure 2. The pumps and IHXs are shown as solid blocks of colour but are in fact hollow cylinders in the model. The thickness of the containment vessel was assumed to be $250 \mathrm{~mm}$; the same as a reactor pressure vessel from a Pressurised Water Reactor (PWR) [11]. The containment vessel is estimated to have a mass of approximately 2000 tonne. The sodium pumps and IHXs are estimated to have steel thickness of $20 \mathrm{~mm}$, similar to the thickness of a steam generator for a PWR [12]. The IHX interior contains approximately 3000 steel tubes $\sim 5.2 \mathrm{~m}$ in length with a $2.7 \mathrm{~cm}$ diameter and steel thickness assumed to be the same as a conventional steam generator, $2.3 \mathrm{~mm}$ [12]. The estimated masses of a pump and an IHX are 11 and 45 tonne, respectively. The volume of the fuel cladding, along with the number of fuel rods, was estimated using the geometry of the ESFR core model developed by D. Thomas [13] to give a total fuel cladding mass of $\sim 16$ tonne. 

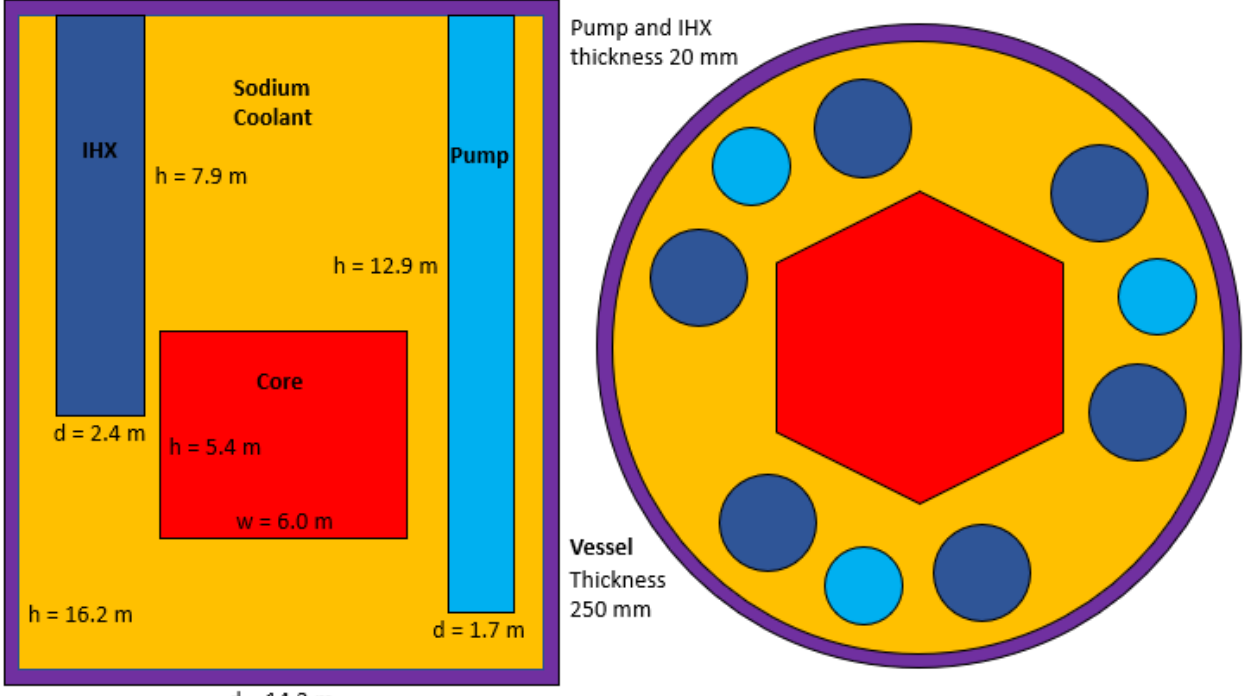

Figure 1. Horizontal and Vertical slice of MCNP Geometry for ESFR Reactor.

\subsection{Simulating the neutron flux distribution through the ESFR}

The particle transport code MCNP6.2 was used to simulate the neutron flux spectra within each of the key reactor components. This simulation involved two modelling steps; the first step employed KCODE (criticality) mode to generate the fission neutron source term which is then used in the second step of modelling as the source for neutron transport throughout the reactor geometry.

\subsubsection{Source term generation}

An MCNP model of the ESFR core, developed by D. Thomas [13] used to study reactivity and power distribution of the ESFR [14], was used to generate the neutron source distribution, Figure 2. This model has used fresh fuel and no consideration has been made for fuel burn up in this study. Table I shows the isotopic composition of the fuel used in the inner and outer fuel assemblies [13].

The criticality functionality of MCNP, KCODE, has the option to generate the neutron distribution using the KSRC card. The KSRC card takes an initial distribution of points within the cells containing fissile material and calculates a new fission source distribution sampling the energy of each neutron from a Watt fission spectrum from the ENDF/B-VII nuclear data library [15]. The fission source distribution is used as the initial distribution in the KCODE cycles. Fission sites for each subsequent cycle are those points generated by the previous cycle. This model ran $500 \mathrm{KCODE}$ cycles each with $1 \times 10^{6}$ particles per cycle generating a source term of $5 \times 10^{8}$ source neutrons for neutron transport. This is a sufficiently large source term for the subsequent neutron transport calculations, resulting in relative errors $<10 \%$ for $>95 \%$ of energy bins in each of the tallies used. Additionally, the KCODE card is used to calculate the average number of neutrons per fission and their average energy. These quantities are used along with the thermal power rating of the reactor, $3600 \mathrm{MW}_{\text {th }}$ [13], to calculate the number of neutrons released in one second of reactor operation, $6.15 \times 10^{20}$ neutrons. The number of neutrons released per second of operation is used to scale the MCNP source term such that tallies used in the neutron transport run are scaled accordingly. 

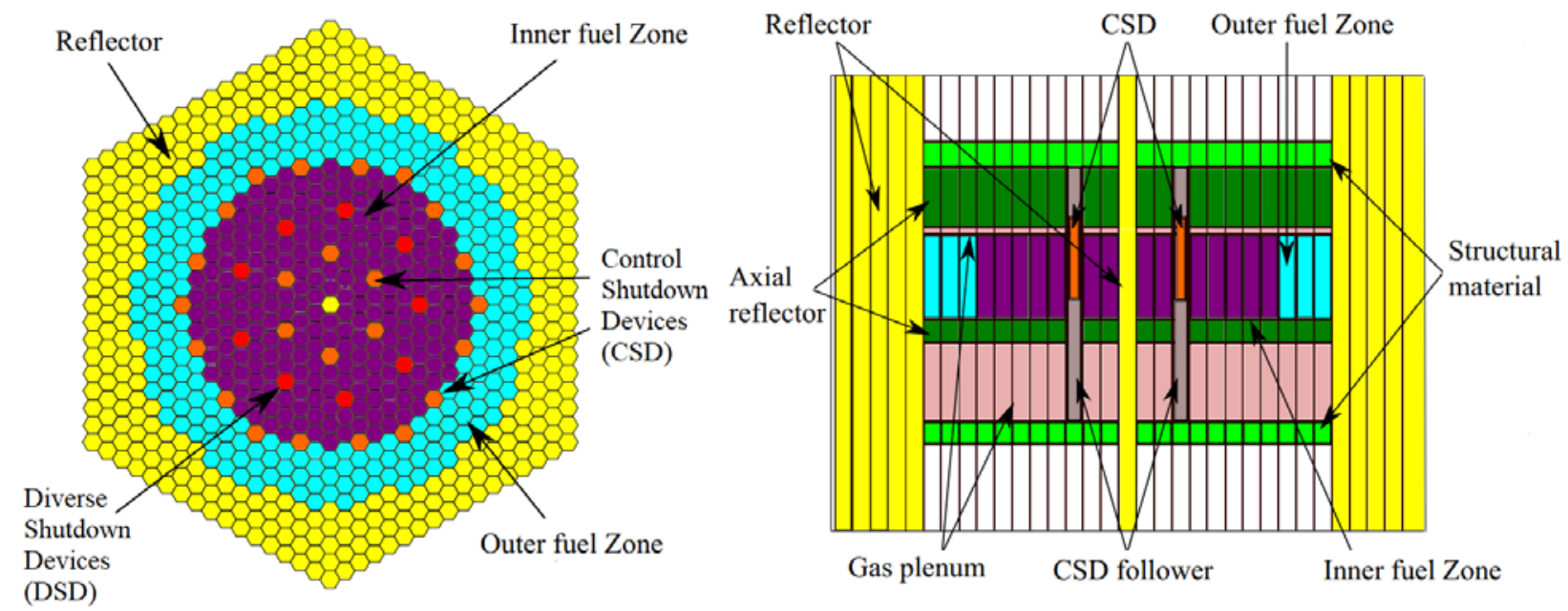

Figure 2. Horizontal and Vertical slice of MCNP Geometry for ESFR Core.

Table I. Fuel Composition: Isotopic composition of fuel used in the ESFR inner and outer fuel assemblies.

\begin{tabular}{|c|c|c|c|c|c|c|c|c|c|}
\hline \multirow{2}{*}{$\begin{array}{c}\text { Fuel } \\
\text { assembly }\end{array}$} & \multicolumn{8}{|c|}{ Isotropic Composition wt\% [14] } \\
\cline { 2 - 10 } & ${ }^{235} \mathrm{U}$ & ${ }^{238} \mathrm{U}$ & ${ }^{238} \mathrm{Pu}$ & ${ }^{239} \mathrm{Pu}$ & ${ }^{240} \mathrm{Pu}$ & ${ }^{241} \mathrm{Pu}$ & ${ }^{242} \mathrm{Pu}$ & ${ }^{241} \mathrm{Am}$ & ${ }^{16} \mathrm{O}$ \\
\hline Inner & 0.19 & 75.09 & 0.46 & 6.12 & 3.83 & 1.06 & 1.34 & 0.1 & 11.81 \\
\hline Outer & 0.18 & 73 & 0.54 & 7.11 & 7.11 & 1.24 & 1.56 & 0.17 & 11.75 \\
\hline
\end{tabular}

\subsubsection{Neutron transport}

The core geometry used in the KCODE simulation was adapted to include simple models of the reactor components; IHXs, pumps and the containment vessel, Figure 1. A 3D model of the ESFR shown in the work of J. Bodi [10] was used to inform the simplified MCNP model. MCNP simulates nuclear reactions within materials, utilising reaction cross sections from nuclear data libraries (see MCNP manual [5] for further details). The material cards used in this model instruct MCNP to use the ENDF/B-VII nuclear data library [15] for cross section sampling. As the temperature varies, from $1500 \mathrm{~K}$ in the fuel to $743 \mathrm{k}$ in the coolant and structural components [13], within the reactor, thermal treatment cards are applied to the uranium dioxide in the fuel and iron in the steel components and the sodium coolant to inform MCNP of the temperature within the material. The thermal treatment cards adjust the neutron elastic scattering cross sections at low energy, sampling the $S(\alpha, \beta)$ cross section from the ENDF/B-VII.0 [16], to account for the kinetic energy of the target nuclides (see MCNP manual [5] for more details).

The F4 tally (see the MCNP manual [5] for details) within MCNP was used to calculate the fluence of neutrons through the volume of the cells that make up the containment vessel, IHXs, pumps and the cladding of 20 different fuel elements. Representative fuel elements were selected to estimate an average flux through the cladding of a fuel element. The 20 fuel elements were all taken from the inner fuel assembly such that the average would be a conservative estimate. For the pumps and IHX's the average flux was taken. Each of the neutron flux tallies are split into the 709-energy bin group structure used in the TENDL-2017 nuclear data library [7]. 


\subsection{Composition of Steel Alloys}

Many steel alloys are currently used in the nuclear industry with more being proposed for future fission and fusion reactors. This work studies seven steels that are currently used in the nuclear industry or are expected to be ready for used in nuclear reactors within the next 10-20 years. The material compositions of the steels are shown in Table II.

Table II. Steel Alloy Compositions: Material composition of steels currently in and proposed for future use in nuclear reactors.

\begin{tabular}{|c|c|c|c|c|c|c|c|c|c|c|c|c|c|c|c|c|c|c|}
\hline \multirow{2}{*}{ Steel } & \multicolumn{10}{|c|}{ Composition* wt\% } & \multirow{2}{*}{ Reference } \\
\cline { 2 - 16 } & $\mathrm{C}$ & $\mathrm{Mn}$ & $\mathrm{P}$ & $\mathrm{S}$ & $\mathrm{Si}$ & $\mathrm{Cr}$ & $\mathrm{Ni}$ & $\mathrm{Mo}$ & $\mathrm{V}$ & $\mathrm{Nb}$ & $\mathrm{B}$ & $\mathrm{N}$ & $\mathrm{Al}$ & $\mathrm{W}$ & $\mathrm{Cu}$ & $\mathrm{Ti}$ & $\mathrm{Zr}$ & \\
\hline $\mathrm{T} 91$ & 0.14 & 0.60 & 0.020 & 0.010 & 0.50 & 9.50 & 0.40 & 1.050 & 0.25 & 0.100 & & 0.070 & 0.02 & & & 0.01 & 0.01 & {$[22]$} \\
\hline $\mathrm{T} 92$ & 0.13 & 0.60 & 0.020 & 0.010 & 0.50 & 9.50 & 0.40 & 0.600 & 0.25 & 0.090 & 0.006 & 0.070 & 0.02 & 2.00 & & 0.01 & 0.01 & {$[22]$} \\
\hline $\mathrm{T} 122$ & 0.14 & 0.70 & 0.020 & 0.010 & 0.50 & 11.50 & 0.60 & 0.300 & 0.10 & 0.005 & 0.100 & 0.100 & 0.02 & 2.50 & 1.70 & 0.01 & 0.01 & {$[22]$} \\
\hline $\mathrm{HT} 9$ & 0.23 & 0.70 & 0.040 & 0.010 & 0.30 & 12.50 & 0.80 & 1.200 & 0.35 & 0.050 & & & 0.03 & 0.60 & & & & {$[23]$} \\
\hline A533B & 0.25 & 1.50 & 0.035 & 0.350 & 0.40 & 0.30 & 0.70 & 0.600 & 0.30 & 0.020 & & & 0.02 & & 0.40 & 0.30 & & {$[24]$} \\
\hline F82H** & 0.10 & 0.10 & 0.005 & 0.002 & 0.10 & 8.00 & 0.03 & 0.001 & 0.20 & 0.0001 & 0.0003 & 0.005 & 0.01 & 2.00 & 0.01 & 0.05 & & {$[25]$} \\
\hline EUROFER $^{* *}$ & 0.11 & 0.40 & 0.005 & 0.005 & 0.05 & 9.00 & 0.01 & 0.005 & 0.20 & 0.005 & 0.002 & 0.030 & 0.01 & 1.10 & 0.01 & 0.02 & 0.05 & {$[26]$} \\
\hline
\end{tabular}

* Balance $\mathrm{Fe}$

** Additional impurities listed in reference.

\subsection{Inventory Simulation}

The inventory simulation software FISPACT-II was implemented to calculate the activation of the steels used in the key reactor components. For each of the reactor components the seven steels described in Table 2 were irradiated in the neutron flux spectrum through the reactor component for a total of 5 full power years. The irradiation schedule for the ESFR in this work has been set such that the ESFR is operating continuously for 5 full power years as this results in a total energy output of $5.66 \times 10^{17} \mathrm{~J}$; equal to the expected total energy output of the European DEMO research reactor through its operational lifetime. Defining the irradiation schedule such that the total energy output is the same between reactors allows for a balanced comparison between the two reactor technologies in terms of mass of ILW and LLW for a set amount of energy generation.

\section{RESULTS AND DISCUSSION}

\subsection{Neutron Spectra Within Reactor Components}

The neutron spectra generated using MCNP for each key ESFR reactor component along with the spectra through the First Wall (FW) and Vacuum Vessel (VV) of the Helium-Cooled Pebble Bed (HCPB) blanket concept for DEMO are presented in Figure 1. The key features of Figure 1 are:

- The total neutron flux through the ESFR fuel cladding is the highest of all the reactor components including the FW of DEMO.

- The neutron flux through the fuel cladding is predominantly in the $10 \mathrm{keV}-10 \mathrm{MeV}$ energy range. 
- The total neutron flux through ESFR components decreases and shifts to the $0.1-10 \mathrm{eV}$ energy range as the distance from the core increases. This is due to neutron scatting and capture in the liquid sodium coolant and other reactor components.

- The fusion spectra have a characteristic $14 \mathrm{MeV}$ peak that is not present in any of the fission spectra, as expected.

- The flux through the FW of DEMO is considerably lower than that through the cladding at energies between $1 \mathrm{keV}$ and $1 \mathrm{MeV}$. Only at the $14 \mathrm{MeV}$ peak is the flux through the FW noticeably higher than the flux through the cladding.

- As expected, the neutron flux through the VV is considerably less than that through the FW, as the FW is designed to be a neutron shield in order to extract energy from the fusion reaction.

- The neutron flux through the VV of DEMO is much higher than that through the ESFR containment vessel at energies above $0.1 \mathrm{keV}$.

- The neutron spectra for the IHXs and the sodium pumps are very similar. At high energies, above $1 \mathrm{keV}$, the spectra through the IHXs and sodium pumps sit between those of DEMOs VV and FW. At low energies, below $0.1 \mathrm{keV}$, the neutron flux through the ESFR IHXs and pumps are higher than in DEMOs VV and FW. This is due to the higher total neutron flux through the fuel cladding.

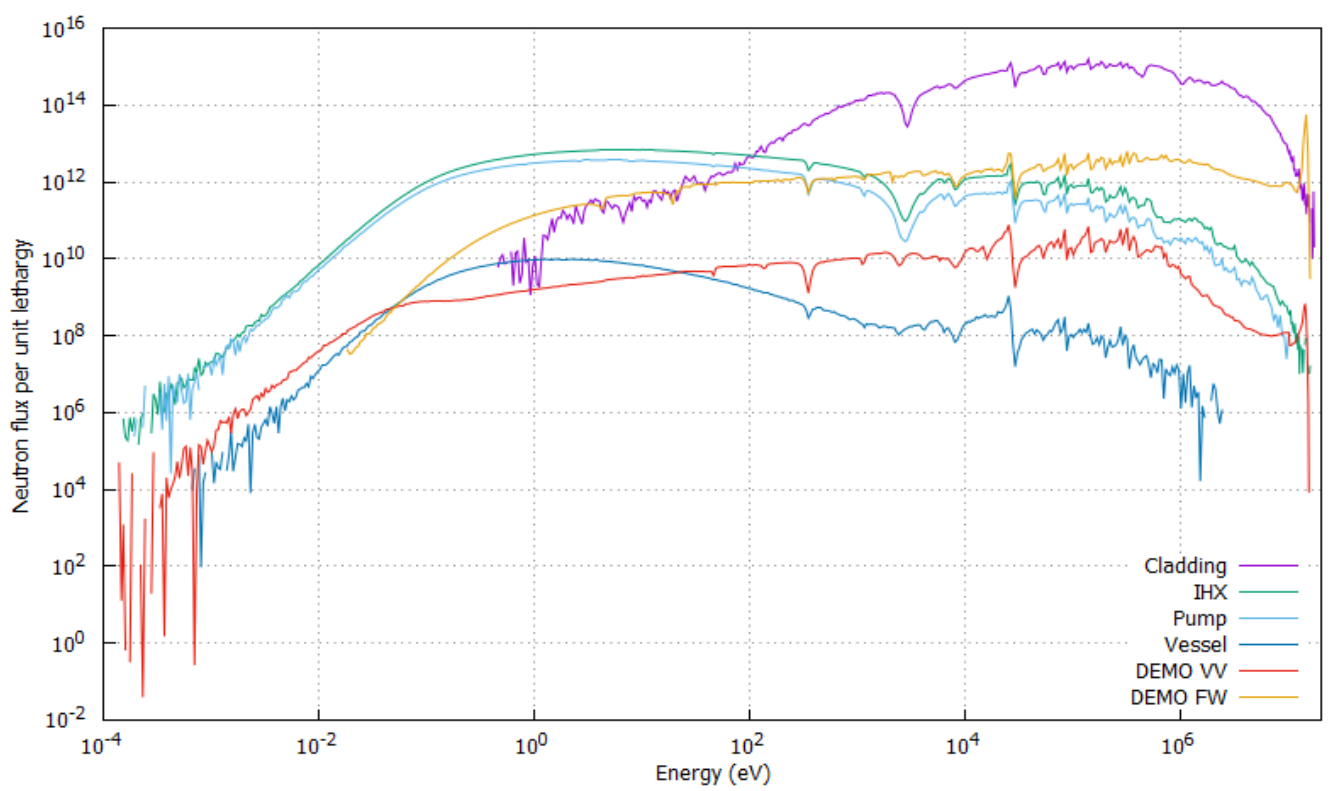

Figure 3. Comparison of Neutron Flux Spectra Within Key ESFR and DEMO Reactor Components.

\subsection{Comparison of Nuclear Industry Steels}

The neutron spectra for the key reactor components, Figure 3 along with a continuous 5 full power year irradiation schedule were used in the FISPACT-II inventory simulation to calculate the total beta and gamma activity of the reactor components for decay times between 1 and 1000 years. Figure 4 compares the activity of the seven steels, for the key reactor components, to the UK-LLW $\beta+\gamma$ activity limit of $1.20 \times 10^{7} \mathrm{~Bq} \mathrm{~kg}^{-1}$ [8]. When considering the $\alpha$ activity, all the steels have a total $\alpha$ activity many orders of magnitude below the LLW limit of $4.00 \times 10^{6} \mathrm{~Bq} \mathrm{~kg}^{-1}$ [8] at all times. The reactor containment vessel becomes classified as LLW after 10 years of decay for all steels, Figure $4 \mathrm{a}$. This is due to the significantly lower neutron flux through the vessel compared to the other reactor components, see Figure 3. 

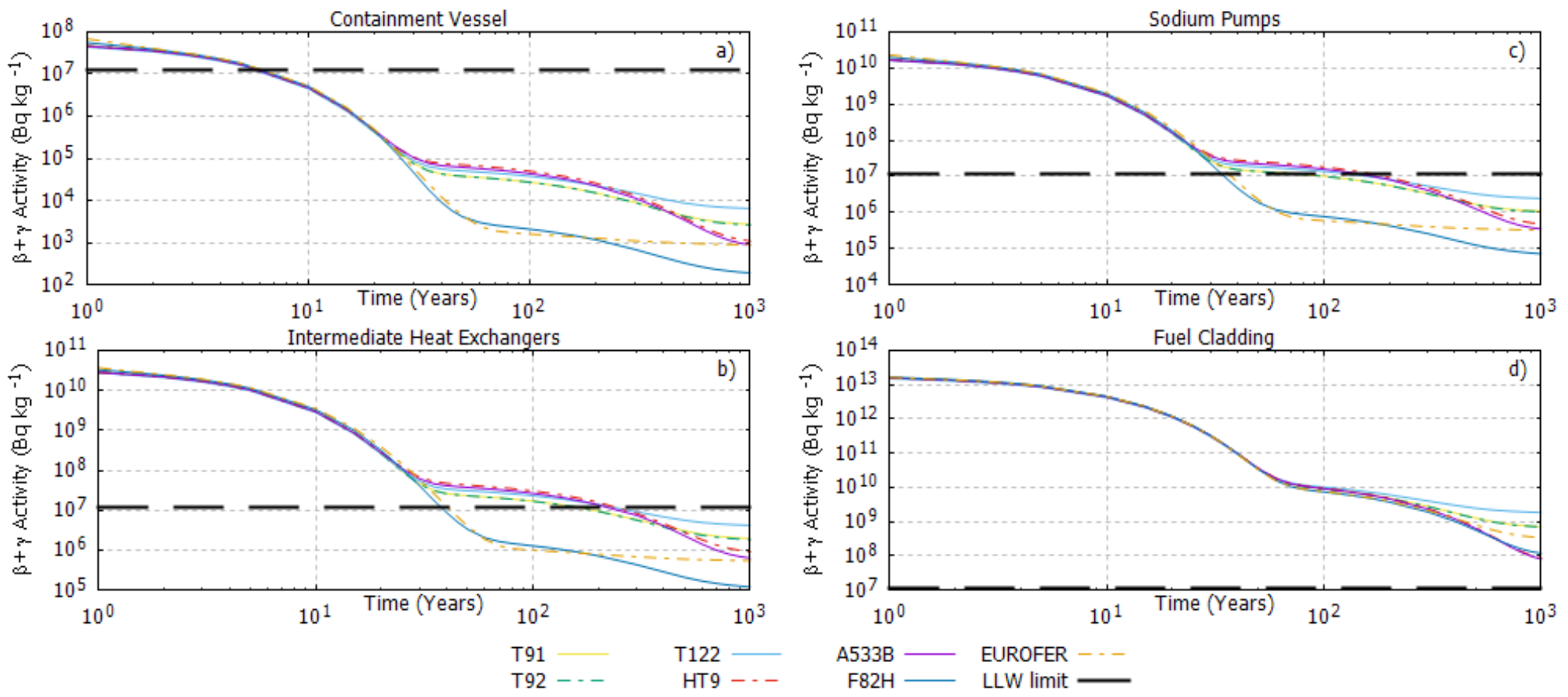

Figure 4. Time Evolution of $\beta+\gamma$ Activity $\left(\mathrm{Bq} \mathrm{kg}^{-1}\right)$ of Nuclear Industry Steels Used in the (a)

Reactor Containment Vessel, (b) Intermediate Heat Exchangers, (c) Sodium Pumps, and (d) Fuel

Cladding of the European Sodium-cooled Fast Reactor. LLW $\beta+\gamma$ Activity Limit Denoted with

Black Dashed Line

\subsubsection{Sodium Pumps and Intermediate Heat Exchangers}

The IHXs and sodium pumps take longer than the vessel, before becoming classified as LLW, due to the higher neutron fluxes through the components. Figures $4 \mathrm{~b}$ and $4 \mathrm{c}$ show a great difference in the time taken for the pumps and IHXs to become classified as LLW between the reduced activation steels, F82H and EUROFER, and the highest activity steels, HT9, A553B, and T122. The reduced activation steels, F82H and EUROFER are classified as LLW after 35-45 years of decay, while HT9, A553B, and T122 require 300 years to become LLW. The steels T91 and T92 have almost identical decay curves; for both steels the pump and IHX are classified as LLW after 80 and 160 years of decay, respectively. For decay times $50-400$ years, ${ }^{63} \mathrm{Ni}$ contributes the highest percentage of the total $\beta+\gamma$ activity for all steels excluding EUROFER. The alloys EUROFER and F82H have comparatively low nickel content in their compositions, Table II, resulting in lower ${ }^{63} \mathrm{Ni}$ (half-life 100 years) activity. The low nickel activity of EUROFER and F82H leads to the pumps and IHXs being classified at LLW much sooner than the steels with higher nickel content. Likewise, the steels HT9, A533B and T122 have the highest nickel content, Table II, and are the last steels to become classified as LLW. The steels T91 and T92 both have $0.4 \% \mathrm{Ni}$; hence they require the same amount of decay time to become classified as LLW. While EUROFER has the lowest nickel content, it contains more nitrogen than the alloy $\mathrm{F} 82 \mathrm{H}$, therefore the ${ }^{14} \mathrm{C}$ (half-life 5730 years) activity, due to the ${ }^{14} \mathrm{~N}(\mathrm{n}, \mathrm{p}){ }^{14} \mathrm{C}$ reaction, of EUROFER is higher than the combined ${ }^{63} \mathrm{Ni}$ and ${ }^{14} \mathrm{C}$ activity of $F 82 \mathrm{H}$. Hence, the total $\beta+\gamma$ activity of F82H drops below the LLW limit approximately 5 years earlier than EUROFER.

\subsubsection{Fuel Cladding}

The activity curves for steels used as fuel cladding within the reactor core are shown in Figure 4d. Due to the high fluence of neutrons in this region of the reactor, none of the steels in this study become classified 
as LLW within 1000 years of radioactive decay. For decay times between 50 and 250 years, there is little difference in the $\beta+\gamma$ activity between the lowest activity steel alloys EUROFER and F82H and the highest activity steels HT9 and T122. For these timescales the dominant nuclide is ${ }^{63} \mathrm{Ni}$ in all the steels. There is a factor of two difference in ${ }^{63} \mathrm{Ni}$ activity between the highest and lowest activity steels after 150 years decay; compared to the factor of 25 difference between the highest and lowest activity steels in the IHX spectra. The neutron spectra in the cladding, Figure 3, shows there is a much higher neutron flux through the cladding and a high percentage of these lie in the $0.01-1 \mathrm{MeV}$ energy range. FISPACT-II pathway analysis shows that there are some long chain reactions involving neutron capture events on $\mathrm{Fe}$ isotopes that produce ${ }^{63} \mathrm{Ni}$ e.g. ${ }^{57} \mathrm{Fe}(\mathrm{n}, \gamma){ }^{58} \mathrm{Fe}(\mathrm{n}, \gamma){ }^{59} \mathrm{Fe}(\beta-)^{59} \mathrm{Co}(\mathrm{n}, \gamma){ }^{60} \mathrm{Co}(\mathrm{n}, \gamma){ }^{61} \mathrm{Co}(\beta-)^{61} \mathrm{Ni}(\mathrm{n}, \gamma){ }^{62} \mathrm{Ni}(\mathrm{n}, \gamma){ }^{63} \mathrm{Ni}$. The $(\mathrm{n}, \gamma)$ cross section for ${ }^{57} \mathrm{Fe},{ }^{58} \mathrm{Fe},{ }^{59} \mathrm{Co},{ }^{61} \mathrm{Ni}$, and ${ }^{62} \mathrm{Ni}$ have resolved and unresolved resonance peaks in the $0.01-1 \mathrm{MeV}$ energy range. Therefore, the high neutron flux in this range in the cladding, orders of magnitudes higher than in the other reactor components, gives rise to large amounts of ${ }^{63} \mathrm{Ni}$ production from iron, hence the similar ${ }^{63} \mathrm{Ni}$ activity across all the steels. While reaction chains such as this results in production of ${ }^{63} \mathrm{Ni}$, the dominant process for ${ }^{63} \mathrm{Ni}$ is neutron capture on nickel isotopes; steels with the highest nickel content have the highest ${ }^{63} \mathrm{Ni}$ activity.

\subsection{Mass and Classification of Waste associated with ESFR}

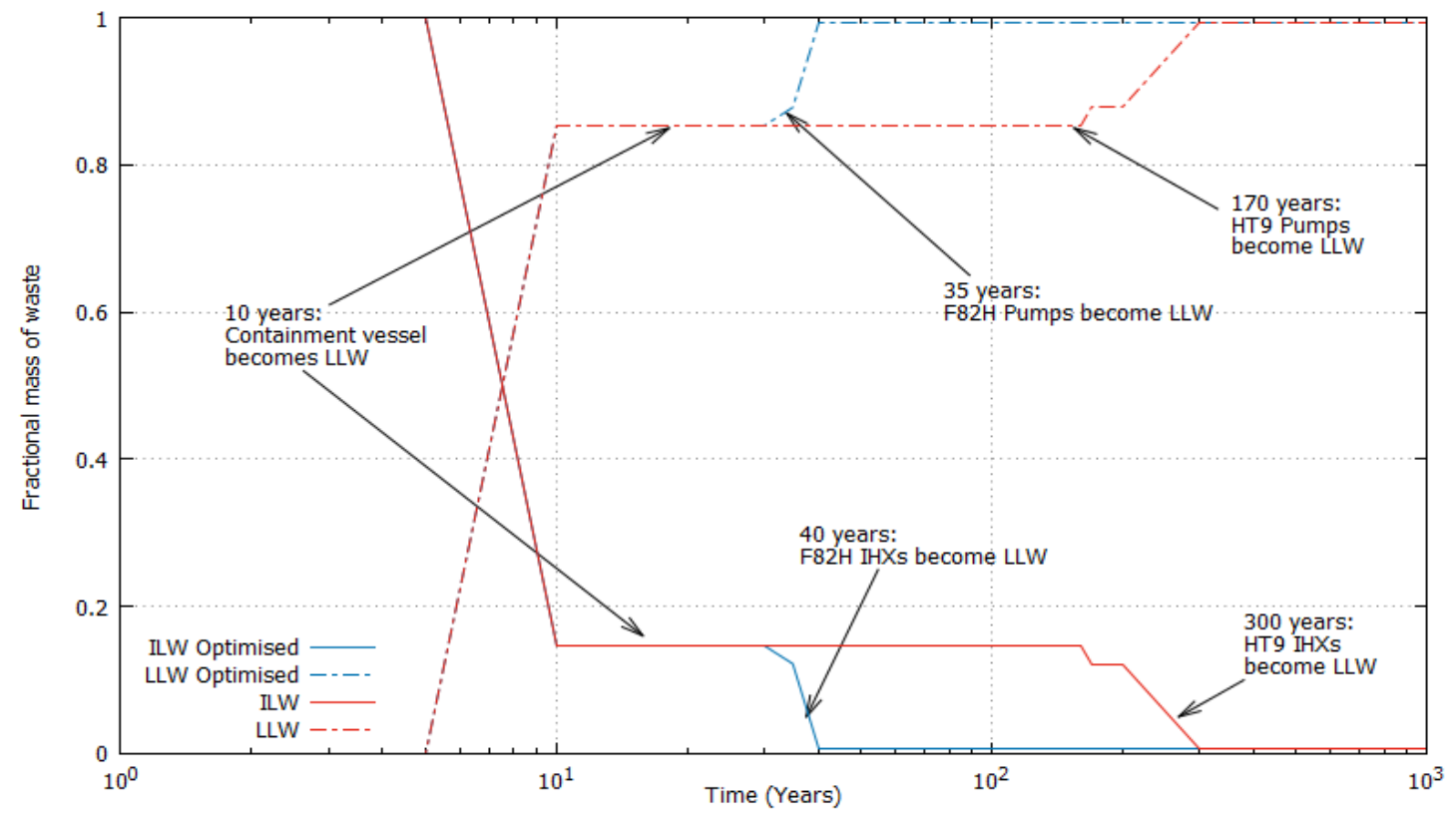

Figure 5. Mass of Low Level and Intermediate Level Waste Associated with the ESFR.

The fraction of LLW and ILW, of the ESFR, as a function of time is plotted in Figure 3. The blue "optimised" curves correspond to the best-case situation in which the, IHXs, pumps are manufactured using the lowest activation steel F82H. The blue curve would only be shifted 5 years later if the IHXs and pumps are manufactured using the alloy EUROFER. The red curves correspond to the worst-case situation where HT9 is the steel of choice for the pumps and IHXs. The red curve is identical if plotted using either A533B or T122 as the steel for the IHXs and pumps. The highest mass component is the containment vessel which becomes classified as LLW after 10 years regardless of which steel is used. Conversely, the lowest mass component, the fuel cladding, remains classified as ILW for over 1000 years irrespective of the steel used. 
It is reasonable to propose that the reactor components would be allowed time, at least 50 years, to decay. This would allow the, "optimised", IHXs and pumps to be disposed, alongside the reactor pressure vessel, in a LLW repository rather than a deep geological disposal facility (GDF) designed for ILW and HAW. The current decommissioning strategy of the UKs Nuclear Decommissioning Authority (NDA) for first generation reactors involves allowing the reactors approximately 100 years to decay before attempting final site clearance, [17]. As the cladding is not expected to be classified as LLW within 1000 years of decay it will likely be disposed of in a GDF as ILW at the time of decommissioning. If the ESFR is manufactured using a reduced activation steel F82H (or EUROFER) for the pumps and IHXs approximately $99 \%$ of the reactor can be disposed of as LLW, with $<1 \%$ disposed as ILW. In the "worstcase" scenario, as shown in blue in Figure 3, the pumps and IHXs are made using a high nickel content steel, HT9, A533B or T122, and require 170 and 300 years decay time respectively before they are classified as LLW. If the decommissioning strategy for the ESFR is like that of the current NDA strategy it would be expected that these components will be disposed in a GDF as ILW along with the fuel cladding. In this "worst-case" scenario approximately $89 \%$ of the reactor can be disposed of as LLW, with $11 \%$ disposed as ILW. Using reduced activation steels such as F82H or EUROFER in the reactor components external to the core results in an order of magnitude reduction in the amount of ILW.

\subsubsection{Waste comparison between the ESFR and DEMO}

Assuming that the DEMO reactor will follow a similar decommissioning timeline to the current NDA strategy, i.e. allowed 100 years decay before decommissioning commences, it is estimated that the HCPB blanket concept for DEMO would have $\sim 35 \%$ of its steels disposed as LLW and the remaining $65 \%$ as ILW [1]. The work carried out by Gilbert et al. [1] used the European Activation File (EAF) nuclear data library EAF-2010 [18] for the FISPACT-II calculations. Differences in inventory simulations due to use of different nuclear data libraries are discussed by Gilbert and Sublet [19]. Compared to the ESFR values which were up to $<11 \%$ in a worst case scenario and $<1 \%$ using reduced activation steels, this is a significantly higher percentage of ILW in the form of activated steels when operated for the equivalent of 5 full power years, such that the energy output of the ESFR is equal to that expected of DEMO over its operational lifetime. The ESFR would likely have an operational lifetime of 40 years [20], this increase in operational time would lead to an increase in the activation of the steels in the ESFR. To more accurately quantify the amount of ILW waste due to activated steels within the ESFR a more thorough investigation, employing the methodology developed by Gilbert et al. [2] would be required. This would include a detailed irradiation schedule for the ESFR that includes shutdown periods for maintenance and refueling along with a more detailed reactor geometry as are employed the waste assessments for DEMO [2].

It is important to recognize that a fusion reactor such as DEMO has no long-lived HAW associated with the fuel. The tritium used in the D-T fusion reaction in DEMO has a short half-life (12.3 years) and is produced in small amounts. The short half-life of tritium means that the tritium activity is reduced by a factor of 280 in the 100 years between reactor shutdown and decommissioning. Therefore, the environmental impact associated with $\mathrm{D}-\mathrm{T}$ fuel for a fusion reactor is low when considering decommissioning time scales of 100+ years. Conversely, while the ESFR will employ a closed fuel cycle to reduce the number of long-lived actinides it will still produce long-lived HAW. Previous work carried out by Fischwick and Anderson [20] assessed the waste arising from all the ESFR fuel over a 40-year operational lifetime; estimating that the ESFR would produce $~ 300$ tonne of long-lived actinides such plutonium and americium with an activity concentration of $3.4 \times 10^{13} \mathrm{~Bq} \mathrm{~kg}^{-1}$. HAW generates significant quantities of heat through radioactive decay for centuries. HAW requires greater degrees of confinement and often it is required that the waste be immobilised and isolated to stop the migration of radiotoxic nuclides such as plutonium. The current strategy for HAW management is to dispose of it in a GDF. Compared to small amounts of short-lived tritium from fusion reactor fuel, the waste burden of the fission reactor fuel is significantly higher. 


\section{SUMMARY AND RECOMENDAIONS}

This work presents an estimate of the waste arisings from activated steels within the ESFR. It is shown that the choice of material for reactor components external to the core, such as the IHXs and sodium pumps, can result in a significant reduction in the percentage of waste disposed as ILW. Manufacturing these components using a low nickel steel such as EUROFER or F82H results in a factor of 10 reduction, compared to high nickel steels such as HT9, in ILW after 50 years of decay time following reactor shutdown. It is important to note that this study does not investigate the suitability of steels in terms of their mechanical or structural performance, the recommendations here are solely based on the level of activation in the steels. This work compares the waste arising from the ESFR to that of DEMO. Activation of steels in DEMO results in a larger fraction of ILW compared to the ESFR. However, the long-lived HAW due to the ESFR fuel poses a significant waste disposal challenge that DEMO does not face.

Research is being carried out into the effects of steel impurities on the activation of fusion reactor steels such as EUROFER [21]. Further developments in material science, manufacturing and nuclear qualification of steels is required if reduced activation steels are to be developed that limit the production of long-lived nuclides, e.g. ${ }^{14} \mathrm{C}$, such that the steels would be classified as LLW under current UK regulations [8]. Such developments would greatly reduce the percentage of waste from fusion reactors disposed of as ILW that requires a GDF like facility. Likewise, to reduce the time required between reactor shutdown and final site clearance for the ESFR, or similar reactors, lower activation steels will be required for use in components such as the IHXs and sodium pumps.

Cooperation with nuclear regulators to assess the waste classification of activated steels based on the risks and environmental impact, rather than the total activity of the waste, would be a positive step towards economical solutions such as a near surface storage facility designed specifically for activated steels. This approach would be beneficial as only the HAW due to the fuel from fast reactors and none of the waste from future fusion reactors would need to be disposed of in a GDF.

\section{ACKNOWLEDGEMENTS}

I would like to thank the nucleargraduates graduate scheme for giving me the opportunity to work with the UKAEA and Magnox Ltd. on this research project.

This work has been part-funded by the RCUK Energy Programme [grant number EP/T012250/1]. To obtain further information on the data and models underlying this paper please contact PublicationsManager@ukaea.uk.

\section{REFERENCES}

1. International Atomic Energy Agency, "Classification of Radioactive Waste," IAEA Safety Standards, General Safety Guide No. GDG-1, 2009.

2. M.R. Gilbert, T. Eade, C. Bachmann, U. Fischer and N.P. Taylor, "Activation, decay heat, and waste classification studies of the European DEMO concept," Nucl. Fusion, 57, 046015 14pp. (2017).

3. OECD Nuclear Energy Agency, "Technology Roadmap Update for Generation IV Nuclear Energy Systems," Generation IV International Forum, January 2014.

4. G. Federici, W. Biel, M.R. Gilbert, R. Kemp, N. Taylor, and R. Wenninger, "European DEMO design strategy and consequences for materials," Nucl. Fusion, 57, 092002 26pp. (2017).

5. Los Alamos National Laboratory, "MCNP6 ${ }^{\mathrm{TM}}$ User's Manual Version 1.0", LA-CP-13-00634, Rev. 0, May 2013. 
6. United Kingdom Atomic Energy Authority, "FISPACT-II User Manual”, UKAEA-R(18)001, February 2018.

7. A.J. Koning and D. Rochman, "Modern Nuclear Data Evaluation With The TALYS Code System", Nuclear Data Sheets 113 (2012) 2841, December 2012.

8. LLW Repository Ltd. "Waste Acceptance Criteria - Low Level Waste Disposal", WSC-WAC-LOWversion 5.0 Issue 1, July 2016.

9. Generation IV International Forum Proliferation Resistance and Physical Protection Evaluation Methodology Working Group, "PR\&PP Evaluation: ESFR Full System Case Study Final Report", GIF/PRPPWG/2009/002, October 2009.

10. J. Bodi, "Development of a CAD model for the European Sodium-cooled Fast Reactor in view of using the thermal hydraulics code TRACE", September 2017.

11. "Reactor pressure vessel," https://www.euronuclear.org/info/encyclopedia/r/reactor-pressurevessel.htm

12. T.K. Mitra, A. Pai and P. Kumar, "Challenges in Manufacture of PFBR Steam Generators," Energy Procedia, 7, pp 317-322, 2011.

13. D.P. Thomas, "Neutronic Analysis of European Sodium-cooled Fast Reactor Using Monte Carlo, May 2015.

14. A. Facchini, V. Giusti, R. Ciolini, K. Tuc`ek, D. Thomas and E. D’Agata, "Detailed neutronic study of the power evolution for the European Sodium Fast Reactor during a positive insertion of reactivity," Nuclear Engineering and Design, 313, pp 1-9, 2017.

15. A. Trkov, M. Herman and D. A. Brown: "ENDF-6 Formats Manual, Data Formats and Procedures for the Evaluated Nuclear Data File, ENDF/B-VI and ENDF/B-VII," BNL-90365-2009, Rev.2, November 2011.

16. M. B. Chadwick, et al. "ENDF/B-VII.0: Next Generation Evaluated Nuclear Data Library for Nuclear Science and Technology", Nuclear Data Sheets UCRL-JRNL-225066, October 2006.

17. Nuclear Decommissioning Authority, "Strategy Effective from April 2016," SG/2016/53, March 2016.

18. Sublet J -Ch, Packer L W, Kopecky J, Forrest R A, Koning A J, and Rochman D A, "The European Activation File: EAF-2010 neutron-induced cross section library", CCFE-R(10)05, 2010.

19. M.R. Gilbert, J.-Ch. Sublet, R.A. Forrest, "Handbook of Activation, Transmutation, and Radiation Damage Properties of the Elements Simulated Using FISPACT-II \& TENDL-2014, Magnetic Fusion Plants", Tech. Rep. CCFE-R (15)26, 2015.

20. S. Fishwick and J. R. Anderson, "European Fast Reactor Waste Arisings", Nuclear Assessments Committee, AEA Safety and Reliability, NAC(91)P18 Revision 1, January 1992.

21. M.R. Gilbert, T.Eade, T. Rey, R. Vale, C. Bachmann, U. Fischer, and N.P. Taylor, "Waste implications from minor impurities in European DEMO materials," Nucl. Fusion 59, 076015 15pp, May 2019.

22. ASTM Standard, "Standard Specification for Seamless Ferritic and Austenitic Alloy-Steel Boiler, Superheater, and Heat-Exchanger Tubes," 2018.

23. Office for Nuclear Regulation, "Review of the iron-based materials applicable for the fuel and core of future Sodium Fast Reactors (SFR)," Research Project ONR-RRR-088, September 2018.

24. R. N. Wright, "Creep of A508/533 Pressure Vessel Steel," Idaho National Laboratory, INL/EXT-1432811 Revision 0, August 2014.

25. A. Hishinuma, A. Kohyama, R. Klueh, D. Gelles, W. Dietz, and K. Ehrlich. "Current status and future R\&D for reduced-activation ferritic/martensitic steels." Journal of Nuclear Materials, 258-263, pp. $193-204,1998$.

26. "Eurofer Steel, Development to Full Code Qualification," Procedia Engineering, 55, pp. 300 -308, 2013. 